\title{
Blood Ferrokinetics in Normal Man*
}

\author{
Fazle Hosain, † George Marsaglia, $\$$ and Clement A. Finch $\S$ \\ (From the Department of Medicine, University of Washington, and the Boeing Scientific \\ Research Laboratories, Seattle, Wash.)
}

\begin{abstract}
Summary. The clearance of radioiron from plasma and its appearance in circulating erythrocytes in normal subjects are studied. The importance of correcting for plasma iron fluctuations and for mean body hematocrit is illustrated. The data are analyzed by probability theory to determine relationships between intravascular and extravascular iron. Two refluxes are described, one of about 7 particles of every 100 leaving the plasma, and the second of about 23. The return times of these are about 5 hours and 8 days, respectively.
\end{abstract}

\section{Introduction}

Various attempts have been made to utilize ferrokinetic measurements to characterize disorders in iron metabolism and, in particular, to quantitate erythropoiesis in normal and anemic subjects (1-5). These calculations, based on the disappearance rate from the plasma of injected radioiron, the total plasma iron level, and the amount of ${ }^{59} \mathrm{Fe}$ localized in the circulating red cells 2 weeks after injection, indicate values of red cell turnover considerably higher than those obtained from such established measurements as the red cell life-span. The reason for this lies in the complexity of internal iron exchange as reflected in the plasma radioiron disappearance. This is not a single exponential, but a complex curve, which reflects both the departure of iron and its constant re-entry into the plasma from the tissues. The purpose of this

* Submitted for publication January 21, 1966; accepted September 14, 1966.

Investigation supported in part by U. S. Public Health Service research grant 5-RO1-HE-06242 and training grant TI-AM-5130. A portion of this work was conducted through the Clinical Research Center of the University of Washington, supported by the National Institutes of Health (grant FR-37).

† Present address: Department of Nuclear Medicine, College of Medical Sciences, Banaras Hindu University, Vanarasi 5, U.P., India.

$\ddagger$ Present address: Boeing Scientific Research Laboratories, Seattle, Wash.

§ Address requests for reprints to Dr. Clement A. Finch, University of Washington School of Medicine, Seattle, Wash. 98105. study was to obtain accurate data about the shape of this curve in normal subjects and to characterize by mathematical analysis the iron exchange between plasma and extravascular sites. A subsequent paper will deal with experimental confirmation of part of the model proposed.

\section{Methods}

The eight subjects were healthy males between the ages of 20 and 30 years. These individuals had no history of anemia and no known significant blood loss or blood donation during the preceding year. Reticulocyte counts were all below $1.5 \%$. Pertinent blood values are shown in Table I.

The format of the study was similar to that described by Huff and co-workers (6) and later modified by Pollycove and Mortimer (4). ${ }^{50} \mathrm{Fe}$ with a specific activity of about $10 \mu \mathrm{c}$ per $\mu \mathrm{g}$ was employed in a dose of approximately $0.5 \mu \mathrm{c}$ per $\mathrm{kg}$. This would give a cumulative marrow dosage of approximately $1.75 \mathrm{rads}(7 a)$. In preparation of the radioiron for intravenous injection, trisodium citrate was added to the radioactive ferric chloride in a molecular ratio of 2 to 1 . This was incubated at room temperature for 30 minutes after mixing with 10 to $15 \mathrm{ml}$ of sterile plasma obtained from normal subjects. The plasma donors had given no evidence of hepatitis virus transmission in prior experiments when their blood had been transfused. After the addition of radioiron, the saturation of the iron-binding capacity of the plasma transferrin did not exceed $70 \%$. A standard was prepared from about $1 \mathrm{ml}$ labeled plasma in a $500-\mathrm{ml}$ volumetric flask containing $0.5 \mathrm{~g}$ EDTA diluted to volume with saline. The remainder of the labeled plasma was injected into the subject. The exact amounts of standard and subject doses were determined by weighing the syringe before and after each injection. 
The labeled plasma was administered at approximately 10:00 a.m. unless otherwise stated. Before injection, a blood sample was drawn for plasma iron and iron-binding capacity measurements, hematocrit, reticulocytes, and background radioactivity determinations. Plasma iron and reticulocyte counts were repeated at 5 and 12 hours during the first day. Blood was drawn into a heparinized syringe 10 minutes after injection of the isotope and frequently thereafter during the first 12 hours, with an average total of 9 samples. Thereafter, samples were taken as indicated in Figure 1 . We were careful to avoid hemolysis, and the blood was rapidly processed. The packed red cell volume of each sample was determined. Radioactivity of the plasma was determined on $2 \mathrm{ml}$ plasma during the first 12 hours and thereafter on $4 \mathrm{ml}$. Two $\mathrm{ml}$ of whole blood corresponding to each plasma sample was hemolyzed by saponin and counted. Also, during the first day, we washed 5-ml samples of whole blood four times with saline before counting to determine the direct radioactive uptake by cellular elements. Urine collected and counted during the first 3 days contained, in all instances, less than $1 \%$ of the injected radioactivity. Cumulative stool losses over the first 10 days in each of four subjects were also less than $1 \%$. An additional 1 to $1.6 \%$ of the isotope injected was removed over 2 weeks through blood sampling in six subjects.

To distinguish between radioactive hemoglobin and transferrin-bound radioiron, we dialyzed plasma samples against a buffer solution containing $0.01 \mathrm{M}$ EDTA and $0.1 \mathrm{M}$ sodium acetate with a $\mathrm{pH}$ of 5.5 to 5.6. A comparison of buffers containing $0.1 \mathrm{M}$ EDTA and varying concentrations of sodium acetate from 0.1 to $0.3 \mathrm{M}$, with the $\mathrm{pH}$ adjusted between 5.5 and 5.6 with acetic acid, showed that there was no significant difference in the amount of iron dialyzed. Radioiron added in vitro to transferrin was more than $98 \%$ dialyzable, whereas hemoglobin iron remained in the dialysis bag. During the first day of the experiment, when the blood contained little or no radioactive hemoglobin, over $95 \%$ of the plasma radioactivity was removed by dialysis. Subsequent

TABLE I

Hematologic and other data on normal subjects.

\begin{tabular}{|c|c|c|c|c|c|c|c|c|}
\hline Subjects & 1 & 2 & 3 & 4 & 5 & 6 & 7 & 8 \\
\hline Weight $(\mathrm{kg})$ & 74 & 84 & 73 & 82 & 84 & 70 & 73 & 78 \\
\hline Initial hematocrit & 45 & 44 & 49 & 47 & 49 & 46 & 46 & 47 \\
\hline Final hematocrit & 43 & 42 & 48 & 45 & 46 & 44 & 44 & 44 \\
\hline Plasma volume $(\mathrm{ml} / \mathrm{kg})$ & 40 & 45 & 35 & 46 & 43 & 41 & 42 & 38 \\
\hline $\begin{array}{l}\text { Initial serum iron }(\mu \mathrm{g} / \\
100 \mathrm{ml})\end{array}$ & 100 & 112 & 99 & 93 & 125 & 130 & 153 & 141 \\
\hline $\begin{array}{l}\text { Mean serum iron* }(\mu \mathrm{g} / \\
100 \mathrm{ml})\end{array}$ & 88 & 97 & & 86 & 99 & 121 & 92 & 139 \\
\hline $\begin{array}{l}\% \text { saturation of trans- } \\
\text { ferrin } \dagger\end{array}$ & 40 & 48 & 34 & 33 & 41 & 52 & 29 & 44 \\
\hline Total blood removed & 255 & 280 & 255 & 265 & 275 & 275 & 295 & 310 \\
\hline
\end{tabular}

* Average values at 0.5 and 12 hours.

† This value at 0 time was obtained by dividing plasma iron by total iron-binding capacity of the plasma.
TABLE II

Nondialyzable plasma radioiron

\begin{tabular}{cccc}
\hline \hline $\begin{array}{c}\text { Time of } \\
\text { sampling }\end{array}$ & $\begin{array}{c}\text { Subject 5 } \\
\text { (dose 30 } \mu \mathrm{c})\end{array}$ & $\begin{array}{c}\text { Subject 6 } \\
\text { (dose 30 } \mu \mathrm{c})\end{array}$ & $\begin{array}{c}\text { Subject with chronic } \\
\text { granulocytic leukemia } \\
\text { in remission } \\
\text { (dose 1,500 } \mu \text { ) }\end{array}$ \\
\hline & $\%$ & $\%$ & $\%$ \\
1-2 hours & 0.7 & 1.3 & \\
5-6 hours & 0.4 & 0.8 & 4.6 \\
20-24 hours & 1.1 & 2.1 & 5.6 \\
2 days & 12.0 & 7.0 & 8.7 \\
3 days & 8.0 & 10.0 & 11.4 \\
4-5 days & & 6.0 & 12.7 \\
7 days & 5.0 & 6.0 & 13.4 \\
9-10 days & 7.0 & 14.0 & 13.8 \\
11-14 days & & & \\
\hline
\end{tabular}

samples through the 2-week period (Table II) showed more activity in the nondialyzable fraction.

We made duplicate counts of 10,000 on each sample obtained in this study, using a well-type scintillation counter with automatic sample changer. ${ }^{1}$ The average background was $220 \mathrm{cpm}$, and the efficiency of the counting was about $25 \%$.

Plasma iron was determined by the method of Bothwell and Mallett (8), and iron-binding capacity was determined by the method of Ressler and Zak (9). Packed cell volumes were obtained by centrifuging the heparinized blood in a Wintrobe hematocrit tube at 2,000 $\mathrm{g}$ for 30 minutes. Values of plasma radioactivity during the first 2 to 3 hours after injection of radioiron were plotted on semilogarithmic graph paper. A straight line was fitted by the method of least squares and extrapolated back to zero time. From this zero time activity and the amount of radioactivity injected, the plasma volume of the recipient was calculated. The half-time for plasma iron clearance was also obtained from the initial slope of this curve. In order to facilitate comparison of the plasma iron curves, we assigned a value of 100 to the extrapolated zero time in each instance; subsequent counts were expressed as percentage of the zero value.

The rate of radioiron disappearance from the plasma is a function of the amount of iron removed per unit time and the amount of iron in the compartment from which it is being lost. Fluctuations in the amount of iron in plasma cause changes in the plasma radioiron curve that are unrelated to the rate of plasma iron exchange. To eliminate the effect of variations in the plasma iron pool, we made adjustments by correcting all plasma iron values to $100 \mu \mathrm{g}$ per $100 \mathrm{ml}$ and changing plasma radioactivity accordingly. Since plasma volume may be assumed to remain relatively constant, adjustments in plasma iron concentration standardized the total plasma iron pool. The following formula was employed: corrected plasma radioactivity $=(100 /$ observed plasma iron in micrograms per $100 \mathrm{ml}) \times$ observed plasma activity.

Plasma iron turnover was calculated from the initial slope of the disappearance curve, and the plasma iron level was calculated as previously described (10). In ad-

1 Model C-120, Nuclear-Chicago, Chicago, Ill. 
dition, the following correction was introduced for a theoretical mean body hematocrit: plasma iron turnover $=$ [ plasma iron $($ micrograms per $100 \mathrm{ml}) \times 0.693 \times 1,440 \times$ $(100-\mathrm{PCV} \times 0.9)] /\left[\mathrm{t}_{\mathbf{1}}\right.$ (minutes) $\left.\times 100\right]$. Here, 0.693 is the natural logarithm of $2 ; 1,440$ is the minutes in 24 hours; and the factor 0.9 is the product of the corrections for trapped plasma (0.98) and mean body hematocrit (0.92). $\mathrm{PCV}=$ packed cell volume.

Red cell utilization was computed from the level of radioactivity reached at 10 to 14 days compared with the plasma $100 \%$ value obtained by extrapolation to time zero. In order to take into account differences in distribution of radioiron in plasma and red cells at the initial and 2-week samplings, we employed the following formula ${ }^{2}$ : red cell utilization $=[($ counts per milliliter blood at 2 weeks $) /($ counts per milliliter blood at 0 time $)] \times$ $[(0.92-0.9 \mathrm{H}) /(1.00-0.9 \mathrm{H})]$.

Mathematical analysis of the plasma iron disappearance curves is based on the following considerations: When an iron particle (complexed iron atom) leaves the plasma, there are two possibilities; 1 ) the iron particle does not return, or 2) the particle returns after a sojourn time outside the plasma. The probability distribution of the sojourn times of returning particles may be calculated in the following manner. Let $f(t)$ be the relative amount of tracer in the plasma after time $t$, with $f(0)=1$. Let $g(x)$ be the density of sojourn times for returning par-

2 Errors in measurements are introduced by plasma trapped in the packed red cells of the hematocrit and by the disparity between venous hematocrit and whole body hematocrit. Because of the latter, initial activity after intravenous injection of radioiron (in plasma) is artificially low and late activity (in red cells) is artificially high. The commonly used factors are 0.98 to adjust for trapped plasma and a factor of 0.92 for converting venous hematocrit to whole body hematocrit. Combining two factors gives the value $0.98 \times 0.92=0.9016$. Thus, if the venous packed cell volume gives a hematocrit reading of $\mathrm{H}$, then we assume that $100 \mathrm{ml}$ of venous blood contains $0.98 \mathrm{H} \mathrm{ml}$ of red cells and $100-0.98 \mathrm{H} \mathrm{ml}$ of plasma, whereas $100 \mathrm{ml}$ of average whole blood contains $0.9016 \mathrm{H}$ $\mathrm{ml}$ of red cells and $100-0.9016 \mathrm{H} \mathrm{ml}$ of plasma. The ratio of the red cell contents of venous and whole body blood is $0.9016 \mathrm{H} / 0.98 \mathrm{H}=0.92$ (formula a), so that the counts per unit volume of venous red cells should be multiplied by 0.92 to adjust to whole body average.

In a similar manner, the ratio of the plasma contents of venous and average whole blood is $(100-0.9016 \mathrm{H}) /(100$ $-0.98 \mathrm{H}$ ) (formula $\mathrm{b}$ ), so that counts per unit volume of venous plasma should be multiplied by this factor to adjust to whole body average. In the complete formula for red cell utilization shown in the text, the correction factors with hematocrit $(H)$ values of $0.40,0.45$, and 0.50 are $0.875,0.865$, and 0.854 .

The formula for red cell utilization is then derived from correction of both the 2 -week red cell radioactive value by formula $a$ and the initial plasma value by formula $b$. The hematocrit employed is that corresponding to the initial sample. ticles. We assume that iron leaves the plasma at a constant rate, and that the feedback of every iron particle leaving the plasma is governed by the same chance mechanism, described by the feed-back density function $g(x)$. Thus, in probability terms, we view plasma iron kinetics in the following way: An iron particle enters the plasma compartment; it spends a random time in the plasma and then leaves. The time spent in the plasma has an exponential distribution. With probability $1-p$, it does not return to plasma, and with probability $\mathrm{p}$ it returns after a random sojourn time whose density function $\mathrm{g}(x)$ we want to determine. The functions $f$ and $g$ are related by this integro-differential equation :

$$
\frac{d f(t)}{d t}=h f(t)+h \int_{0}^{t} f(x) g(t-x) d x,
$$

where $-h$ is the initial slope of $f(t)$, that is, $h=-f^{\prime}(0)$. The first term on the right of Equation 1 indicates that tracer is lost from the plasma at the rate of $h$ times the amount present, and the second integral term represents the cumulative feedback. To illustrate the feedback term, say at $t=8$ hours, we have:

$$
\begin{aligned}
\mathrm{h} \int_{0}^{8} \mathrm{f}(x) \mathrm{g}(\mathrm{t}-x) \mathrm{d} x \cong & \mathrm{hf}(1) \mathrm{g}(7)+\mathrm{hf}(2) \mathrm{g}(6) \\
& +\mathrm{hf}(3) \mathrm{g}(5)+\cdots+\mathrm{hf}(7) \mathrm{g}(1)
\end{aligned}
$$

The terms on the right show that at $t=8$ hours, the feedback is made up of the amount received 7 hours before [hf(1)] times the proportion of that amount which is to be returned $[g(7)]$ plus the amount received 6 hours before $[\mathrm{hf}(2)]$ times the proportion of that amount which is to be returned $[\mathrm{g}(6)]$, and so forth.

Equation 1 may be solved numerically or by fitting the data that give the plasma iron disappearance curve $f(t)$ with a linear combination of exponential functions, in which case $g(x)$ will be a linear combination with one less exponential. Details of the mathematical approach have been presented (11). The area under the extracted curve $g(x)$ gives the proportion of particles that are fed back, i.e., the probability $p$ that a particle will be fed back.

\section{Results}

The plasma iron disappearance and red cell radioactivity curves from six normal subjects are summarized in Figures 1 to 3 . Some of the significant features of the plasma disappearance curve are summarized in Table III. The disappearance rate of radioiron from plasma $\left(t_{\frac{1}{2}}\right)$ varied from 70 to 105 minutes, and the calculated plasma iron turnover varied from 0.70 to $0.86 \mathrm{mg}$ per $100 \mathrm{ml}$ whole blood per day. The slope of the disappearance curve had notably decreased after 3 to 5 hours, and during the second week, when the plasma radioactivity was approximately $0.1 \%$ of the original level, the slope corresponded to a half- 
time of 7 or more days. There was initially a lo- by reticulocytes. Activity was detectable in red calization of 0.1 to $0.2 \%$ of the injected activity in cells by 8 to 12 hours and increased thereafter to a the buffy coat, partly due to direct uptake of iron total of 80 to $85 \%$ of the iron injected.

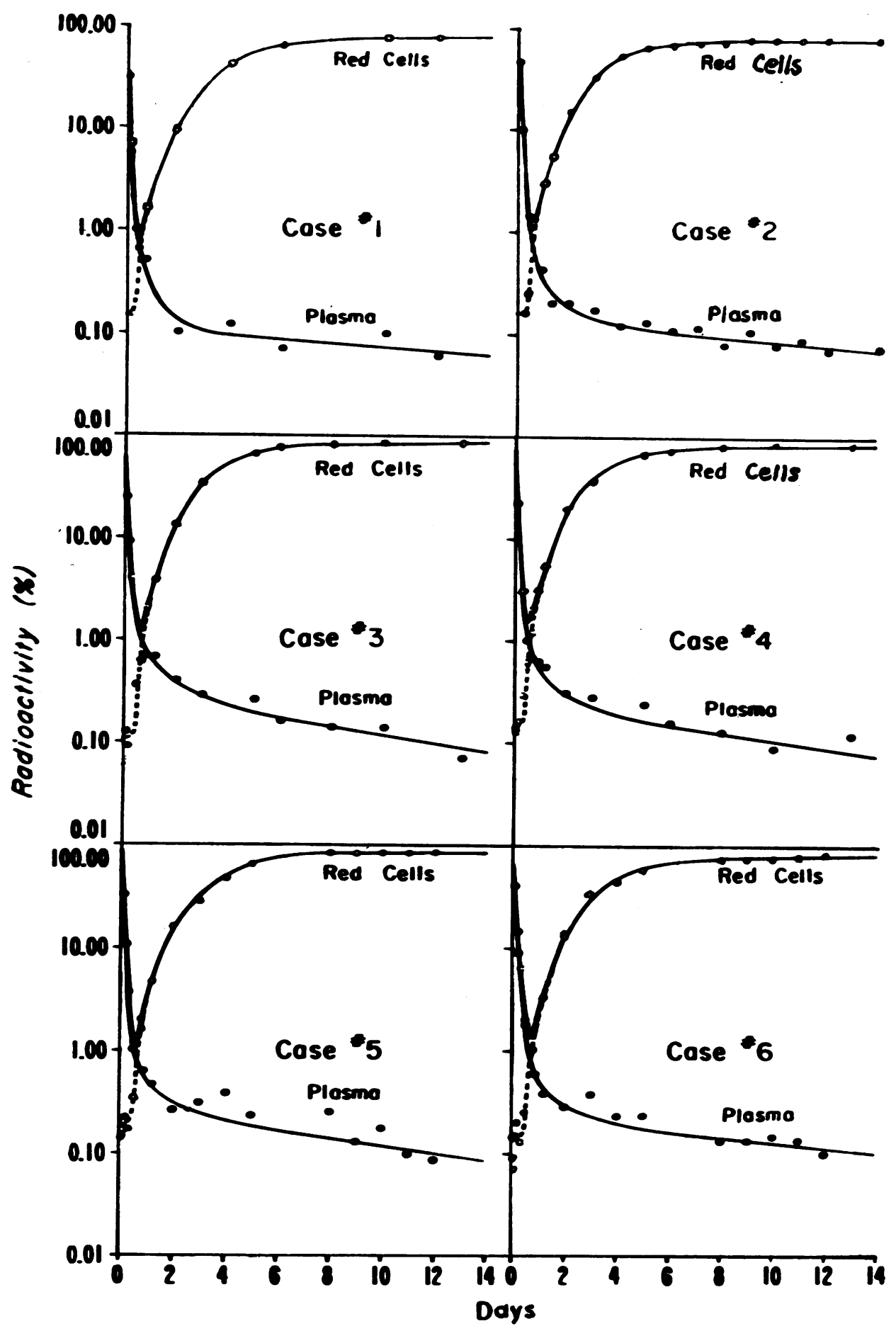

Fig. 1. BLood RAdioiron Kinetics over a 14-DAY PERIod. Plasma disappearance curves are shown by solid dots and red cell activity by open circles. 


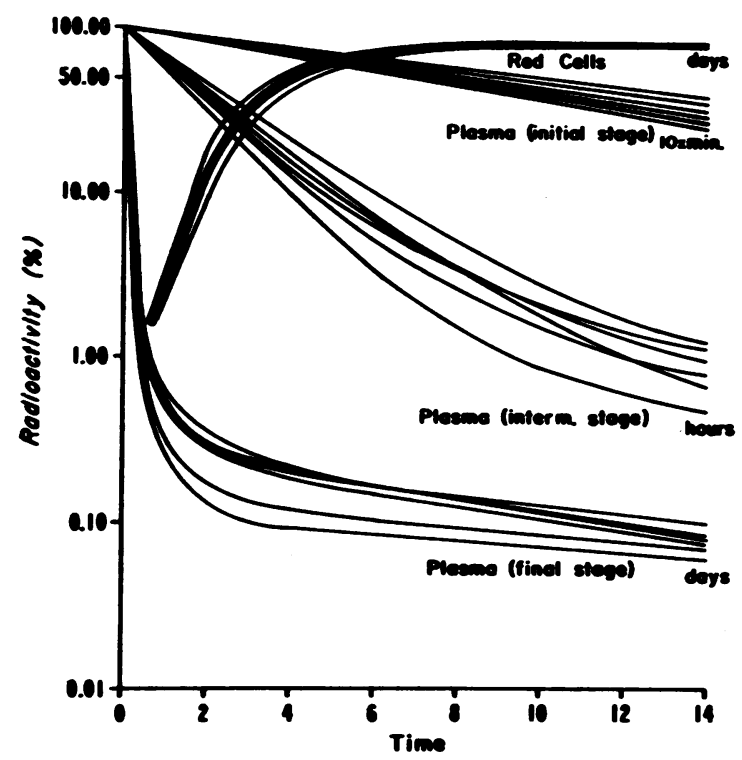

Fig. 2. Blood ferrokinetics Plotted on three DifferENT TIME SCALES AS SPECIFIED.

One of the important variables in the portrayal of movement of iron through the plasma is the plasma iron level. To evaluate the effect of fluctuations of plasma iron on the disappearance rate, plasma iron was measured at the time of each blood sampling in two additional subjects. The data before and after correction for plasma iron fluctuations in Subject 7 are shown in Figure 4. It is apparent that this correction both improves the fit of individual points with the drawn curve and modifies the shape of the curve.

Mathematical interpretations. The initial curves plotted in Figure 1 were subjected to mathematical analysis employing probability theory in which we assumed that there was a steady state of iron exchange and that the shape of the plasma iron disappearance curve was due to feedback into plasma. The reflux was separable into two distinct

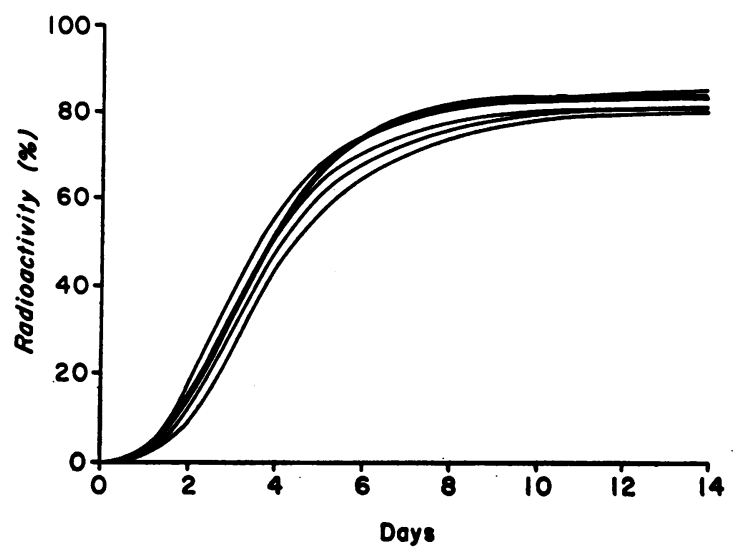

Fig. 3. Red cell Radioactivity plotted on Cartesian COORDINATES.

parts. Both of these refluxes had the general characteristics of exponential functions. The computations are best illustrated by a specific example (Subject 3). As indicated in Methods, the data are plotted on semilogarithmic paper, and a linear combination of three exponentials is fitted. For the data of Subject 3, the fitted function is:

$$
f(t)=0.9776 \mathrm{e}^{-13.0 t}+0.01843 \mathrm{e}^{-1.74 t}+0.0040 \mathrm{e}^{-0.124 t} .
$$

With this $f$ in the integro-differential equation

$$
f^{\prime}(t)=-h f(t)+h \int_{0}^{t} f(x) g(t-x) d x,
$$

the solution for the feedback function is

$$
g(x)=0.189 \mathrm{e}^{-1.25 x}+0.040 \mathrm{e}^{-0.168 x},
$$

which we write in the form

$$
g(x)=0.097\left(1.95 \mathrm{e}^{-1.85 x}\right)+0.238\left(0.169 \mathrm{e}^{-0.188 x}\right) .
$$

The area under $\mathrm{g}(x)$ is $0.097+0.238=0.335$, which means that $33.5 \%$ of the iron leaving plasma is fed back. Since $g(x)$ is a mixture of

\begin{tabular}{|c|c|c|c|c|c|c|}
\hline Subjects & 1 & 2 & 3 & 4 & 5 & 6 \\
\hline $\begin{array}{l}\text { Initial plasma iron clearance rate }\left(\mathrm{t}_{\mathbf{l}} \text {, minutes) }\right. \\
\text { Plasma iron turnover }(\mathrm{mg} / \mathrm{day} / 100 \mathrm{ml} \text { whole blood) } \\
\text { Red cell radioactivity at } 2 \text { weeks }(\%) \\
\text { Initial direct cell uptake }(\%) \\
\text { Minimal whole blood isotope level }(\%) \\
\text { Plasma radioactivity level at } 12 \text { hours (\% of } 0 \text {-hour level) } \\
\text { Plasma radioactivity level at } 12 \text { days (\% of } 0 \text {-hour level) } \\
\text { Time of minimal blood activity (hours) }\end{array}$ & $\begin{array}{l}70.0 \\
0.86 \\
78 \\
0.15 \\
0.8 \\
0.63 \\
0.068 \\
12\end{array}$ & $\begin{array}{l}86.0 \\
0.79 \\
79 \\
0.16 \\
1.0 \\
1.35 \\
0.077 \\
12\end{array}$ & $\begin{array}{l}80.0 \\
0.70 \\
84 \\
0.11 \\
1.2 \\
1.50 \\
0.096 \\
14\end{array}$ & $\begin{array}{l}76.0 \\
0.71 \\
81 \\
0.15 \\
1.6 \\
1.03 \\
0.090 \\
12\end{array}$ & $\begin{array}{l}95.0 \\
0.75 \\
83 \\
0.18 \\
1.0 \\
1.05 \\
0.102 \\
16\end{array}$ & $\begin{array}{c}105.0 \\
0.73 \\
80 \\
0.14 \\
1.3 \\
1.75 \\
0.114 \\
16\end{array}$ \\
\hline
\end{tabular}
two exponential functions, one with an average

TABLE III

Data derived from the plasma and red cell radioiron curves 


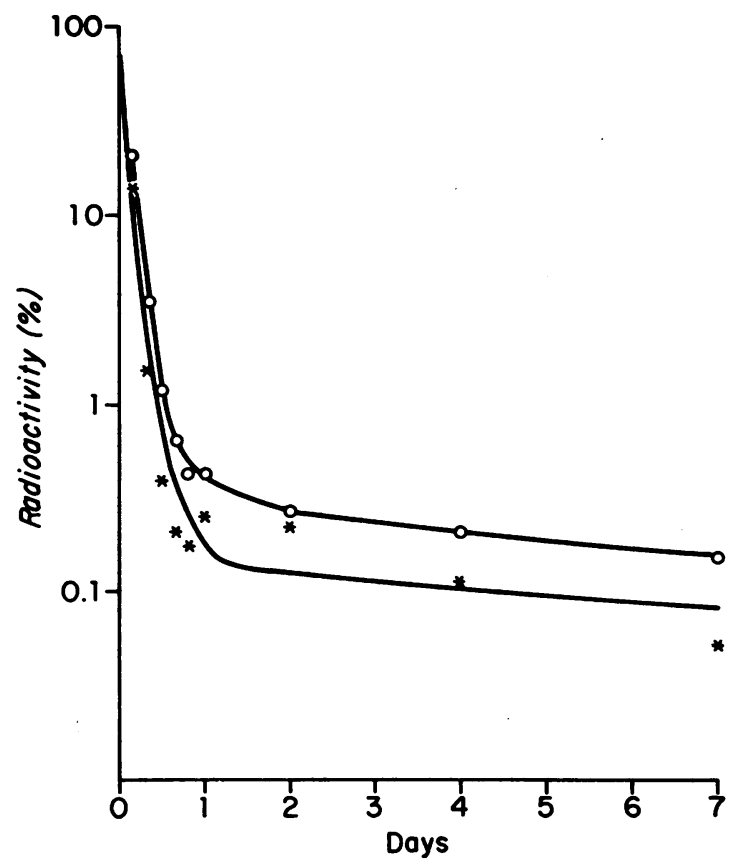

Fig. 4. Plasma radioiron disappearance curve in a NORMAL SUBJECT (No. 7) AS AFFECTED BY FLUCTUATIONS IN PLASMA IRON. Uncorrected points are shown as asterisks, and the corrected points by open circles.

life of $1 / 1.95=0.51$ days, the other with an average of $1 / 0.169=5.9$ days, the easiest way to interpret $g(x)$ is to assign two exponential feedback mechanisms. Thus, of every 100 particles leaving the plasma, 33.5 are fed back; of those fed back, 9.7 return after an exponential sojourn with a mean of 0.51 days or 12.3 hours, and 23.8 return after an exponential sojourn with a mean of 5.9 days. This is the most convenient way of interpreting sojourn distributions made up of a mixture of two exponential densities. There are, of course, many other possible feedback mechanisms that could yield such a composite $\mathrm{g}(\boldsymbol{x})$. We have, however, evidence for singling out one of the components of $g(x)$ on the basis of further studies which show that about $10 \%$ of the iron which leaves the plasma on the transferrin molecule returns still bound to the original molecule after a half-life of about 6 hours. There is a greater degree of uncertainty in the longer component of $g(x)$, however. In Patient 3, this component appears to be exponential with a mean sojourn of around 6 days, but the duration of the experiment ( 14 days) and the uncertainty of data collected from the tail of the disappearance curve do not permit us to resolve this component with the same precision as the shorter component. There could be several feedback mechanisms with sojourn times of 4 to 12 days, and the composite effect might show up in a limited set of data as a single component with a sojourn of about 8 days.

Results of similar calculations made on the other Seattle subjects are summarized in Table IV. Of 100 particles leaving the plasma, an average of 31 appeared to return. The rapid reflux represented a return of about eight particles with an average sojourn time of 11 hours or average $t_{\frac{1}{2}}$ of 7.6 hours. The slow fraction consisted of 23 particles with an average sojourn time of 8 days, or average $t_{1}$ of 5.5 days.

This initial expression is inadequate, however, in that it does not take into consideration the effect of diurnal variations in plasma iron, which have been found to be largely due to variations in entrance of iron into plasma rather than changes in amount of iron leaving plasma (12). The calculations of reflux in two subjects before and after these corrections are shown in Table IV.

\section{Discussion}

Any formulation of the ferrokinetics in normal man has limitations imposed by the precision of the data obtained and the way in which these data

TABLE IV

Iron reflux as computed from data in normal man

\begin{tabular}{|c|c|c|c|c|c|c|c|}
\hline & \multirow[b]{2}{*}{$\begin{array}{c}\text { Total } \\
\text { feedback }\end{array}$} & \multicolumn{3}{|c|}{ Rapid component } & \multicolumn{3}{|c|}{ Slow component } \\
\hline & & $\%$ & $\begin{array}{l}\text { Average } \\
\text { sojourn }\end{array}$ & $t_{3}$ & $\%$ & $\begin{array}{c}\text { Average } \\
\text { sojourn }\end{array}$ & $t_{1}$ \\
\hline & $\%$ & & hours & & & days & \\
\hline \multicolumn{8}{|c|}{ New York* } \\
\hline FA & 68 & 37 & 7 & 4.9 & 31 & 3.5 & 2.4 \\
\hline $\mathbf{A M}$ & 52 & 25 & 6.4 & 4.4 & 27 & 4.6 & 3.2 \\
\hline SH & 39 & 18 & 8 & 5.5 & 21 & 2.3 & 1.6 \\
\hline ER & 59 & 29 & 6.4 & 4.4 & 30 & 2.9 & 2.0 \\
\hline Huff & 47 & 15 & 18 & 12.5 & 32 & 5.2 & 3.6 \\
\hline \multicolumn{8}{|l|}{ Seattle } \\
\hline 1 & 31 & 9.4 & 9 & 6.2 & 21.6 & 11 & 7.6 \\
\hline 2 & 26 & 6 & 10 & 6.9 & 20 & 10 & 6.9 \\
\hline 3 & 34 & 10 & 12 & 8.3 & 24 & 5.9 & 4.1 \\
\hline 4 & 34 & 7 & 13 & 9.0 & 27 & 6.4 & 4.4 \\
\hline 5 & 31 & 4 & 19 & 13.2 & 27 & 8 & 5.5 \\
\hline 6 & 33 & 8 & 13 & 9.0 & 25 & 7.3 & 5.1 \\
\hline 7 & 21 & 5.5 & 5 & 3.5 & 15.5 & 5.4 & 3.7 \\
\hline 8 & 23 & 7.0 & 4.4 & 3.0 & 16 & 8.9 & 6.6 \\
\hline $7 \dagger$ & 20 & 2.0 & 8.6 & 6.0 & 18 & 9 & 6.2 \\
\hline $8+$ & 24 & 3.0 & 16 & 11.0 & 21 & 7.7 & 5.3 \\
\hline
\end{tabular}

* Data supplied by Dr. Louis Wasserman, Mount Sinai Hospital, New York, N. Y.

† Adjusted for plasma iron variations. 

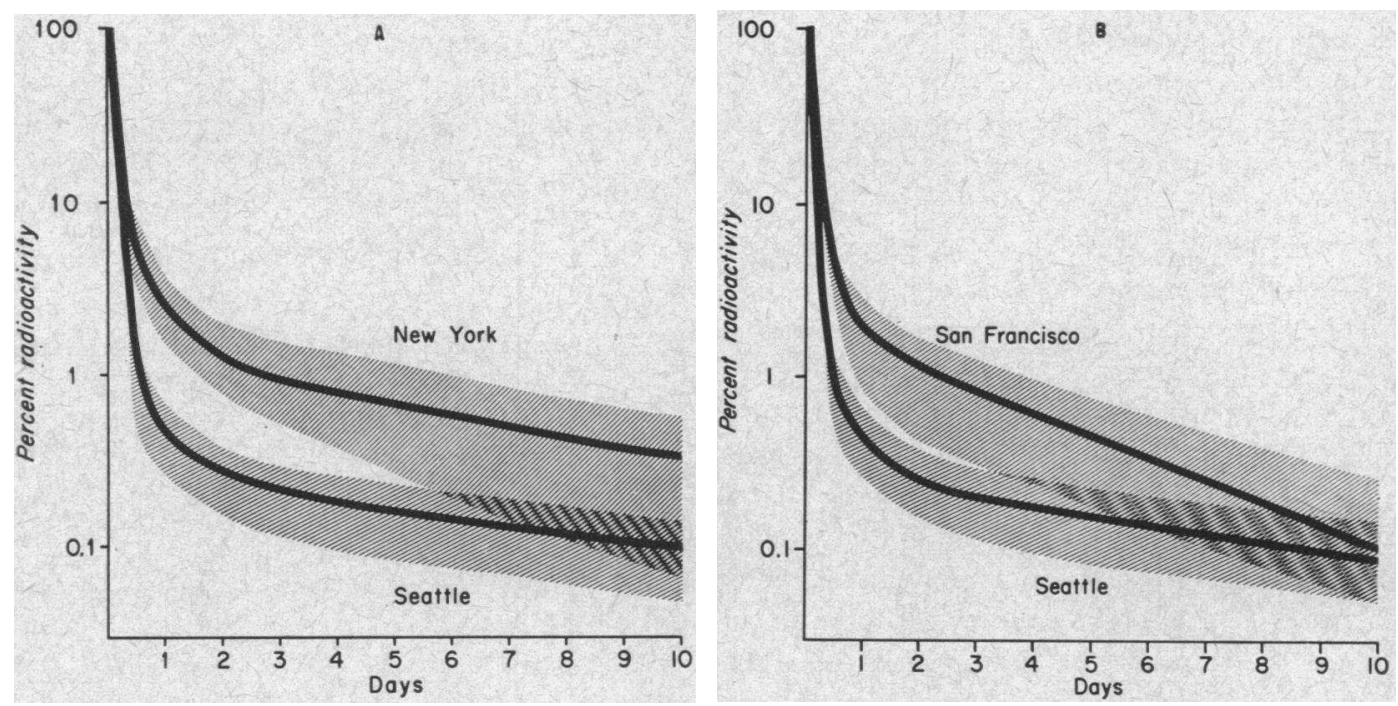

Fig. 5. Average Plasma RadioIron disappearance CURVES in Which SHADEd area REPRESENTS RANGe. Section A shows comparison between New York and Seattle data, and section B compares San Francisco (4) and Seattle data.

are expressed. In this study, the amount of isotope employed gave reasonable counting accuracy. After the third day, counts were low, but enough activity was present to provide theoretical counting accuracy of better than $\pm 10 \%$. During the latter phase of the study hemolysis presented difficulties, since the red cell activity at that time was several hundredfold that of the plasma. An improved fit of the data was obtained by a dialysis technique that permitted correction for activity present as hemoglobin iron. It is entirely possible that a small fraction of hemoglobin activity might be due to in vivo breakdown of red cells, such as that which occurs in certain pathologic states (13). Further studies employing more sensitive counting techniques (14) and greater precautions to prevent hemolysis will be required to solve this problem.

There is a hidden error due to differences between venous hematocrit and hematocrit in other parts of the vascular system (15). Formulas for making these corrections have been supplied. In the calculation of plasma iron turnover, the adjustment of the amount of plasma in blood, allowing for mean body hematocrit, alters the average plasma iron turnover from 0.69 to $0.76 \mathrm{mg}$ turnover per day per $100 \mathrm{ml}$ whole blood. Likewise, red cell utilization is changed to an average of $81 \%$ when corrections are made in the initial plasma and in the final red cell activity for mean body hematocrit.

When clearance data obtained in normal subjects by different investigators $(1,3-5)$ are examined, a general similarity is found among all published curves. There is continual decreasing clearance rate, changing from an original half-time of a few hours to several days. However, as indicated in Figure 5 and Table IV, differences between the individual groups are greater than those among individual subjects within each group. The reason for such differences is not apparent; they cannot be correlated with variation in the plasma iron levels, nor are they due to errors introduced in isotope counting, since samples representing a complete study of one subject, which were counted both in this laboratory and in another, ${ }^{8}$ gave similar results. Such discrepancies should be resolved before "normal" data can be accepted as completely valid.

In approaching the analysis of the iron clearance curves, one of the first considerations is the nature of plasma radioactivity. Our earlier studies (16) indicate that in normal animals and man, virtually all plasma radioactivity is transferrin bound and the shape of the tracer disappearance curve is due to re-entry of radioactivity into plasma

${ }^{3}$ Dr. Louis Wasserman, Mount Sinai Hospital, New York, N. Y. 
rather than nonhomogeneous clearance. One may then consider a system in which iron is leaving a single plasma pool at a constant rate; most of this iron will become fixed in red cells, but a certain portion returns to plasma. Prior attempts to visualize iron kinetics $(2-4)$ have assumed various multiple pool exchanges with plasma and have empirically fitted data to these models. Such an approach, in effect, sets up a hypothesis which can then be subject to experimental verification. For example, Pollycove and Mortimer (4) have devised a model predicated on the basis of a labile iron pool in the marrow, a supposition that was not supported by direct examination of the marrow for such a pool (17). In the present analysis, it was only necessary to make the single assumption that the processing of iron continued at a constant rate through the experimental period. No extravascular pools were assumed, but rather the per cent returned and the density of this return in respect to time were analyzed by probability theory. There appeared to be two distinct refluxes, a rapid one of about $7 \%$ and a slow one of about $23 \%$. These two distinguishable populations of returning particles would be consistent with the three exponentials that may be drawn from the plasma iron disappearance curve.

These calculations are distorted by alterations in plasma iron concentration. There is an average diurnal variation of about $40 \%$, and irregular fluctuations also occur $(7 b, 18)$. These changes are generally considered to be less related to a change in the amount of iron leaving the plasma per unit time than to the variable release of iron from the reticuloendothelial cells $(7 b)$. When the plasma iron pool was stabilized by adjusting the plasma iron values to 100 , the fall in plasma radioactivity became slower during the first day, and mathematical analysis showed a reduction of over half in the rapid reflux component, whereas the slow reflux appeared somewhat increased. Even with this adjustment, however, there remained two separable mechanisms by which iron is returned to the plasma. Each of these refluxes appears to fall off exponentially with time. It is not possible, from existing data, to define their exact contour or to determine whether they represent a single process or are each actually composed of multiple components. It is not possible to define the anatomic nature of the exchange of these two refluxes.
However, the magnitude of the rapid reflux is similar to the rate of extravascular exchange of transferrin of about 5\% observed by Katz (19) and by Awai and Brown (20).

\section{References}

1. Huff, R. L., T. G. Hennessy, R. E. Austin, J. F. Garcia, B. M. Roberts, and J. H. Lawrence. Plasma and red cell iron turnover in normal subjects and in patients having various hematopoietic disorders. J. clin. Invest. 1950, 29, 1041.

2. Huff, R. L., and O. J. Judd. Kinetics of iron metabolism in Advances in Biological and Medical Physics, John H. Lawrence and Cornelius A. Tobias, Eds. New York, Academic Press, 1956, vol. 4, p. 223.

3. Wasserman, L. R., L. Sharney, N. R. Gevirtz, L. Schwartz, L. R. Weintraub, D. Tendler, A. E. Dumont, D. Dreiling, and M. Witte. Studies in iron kinetics: I. Interpretation of ferrokinetic data in man. J. Mt Sinai Hospital 1965, 32, 262.

4. Pollycove, M., and R. Mortimer. The quantitative determination of iron kinetics and hemoglobin synthesis in human subjects. J. clin. Invest. 1961, 40, 753.

5. Dern, R. J., A. Monti, and M. F. Glynn. Studies with doubly labeled iron. IV. Evidence for a second iron-binding system in plasma. J. Lab. clin. Med. 1963, 61, 280.

6. Huff, R. L., P. J. Elmlinger, J. F. Garcia, J. M. Oda, M. C. Cockrell, and J. H. Lawrence. Ferrokinetics in normal persons and in patients having various erythropoietic disorders. J. clin. Invest. 1951, 30, 1512.

7. Bothwell, T. H., and C. A. Finch. Iron Metabolism. Boston, Little, Brown, 1962, a) p. 35, b) p. 152.

8. Bothwell, T. H., and B. Mallett. The determination of iron in plasma or serum. Biochem. J. 1955, 59, 599.

9. Ressler, N., and B. Zak. Serum unsaturated ironbinding capacity. Amer. J. clin. Path. 1958, 30, 87.

10. Bothwell, T. H., A. V. Hurtado, D. M. Donohue, and C. A. Finch. Erythrokinetics. IV. The plasma iron turnover as a measure of erythropoiesis. Blood 1957, 12, 409.

11. Marsaglia, G. Stochastic analysis of multi-compartment systems. Boeing Scientific Research Laboratories, Math Note D1-32-0280, Seattle, 1963.

12. Hosain, F., G. Marsaglia, and C. A. Finch. Unpublished data.

13. Gevirtz, N. R., L. R. Wasserman, L. Sharney, and D. Tendler. Studies of plasma $\mathrm{Fe}^{50}$ disappearancea manifestation of ineffective erythropoiesis and of hemolysis. Blood 1965, 25, 976.

14. Katz, J. H., M. Zoukis, W. L. Hart, and R. J. Dern. A simplified procedure for the simultaneous as- 
say of $\mathrm{Fe}^{55}$ and $\mathrm{Fe}^{50}$ in a liquid scintillation system. J. Lab. clin. Med. 1964, 63, 885.

15. Mollison, P. L. Blood Transfusion in Clinical Medicine, 3rd ed. Oxford, Blackwell, 1961.

16. Hosain, F., and C. A. Finch. Ferrokinetics : a study of transport iron in plasma. J. Lab. clin. Med. 1964, 64, 905.

17. Noyes, W. D., F. Hosain, and C. A. Finch. Incorporation of radioiron into marrow heme. $\mathrm{J}$. Lab. clin. Med. 1964, 64, 574.
18. Hamilton, L. D., C. J. Gubler, G. E. Cartwright, and M. M. Wintrobe. Diurnal variation in the plasma iron level of man. Proc. Soc. exp. Biol. (N. Y.) 1950, 75, 65.

19. Katz, J. H. Iron and protein kinetics studied by means of doubly labeled human crystalline transferrin. J. clin. Invest. 1961, 40, 2143.

20. Awai, M., and E. B. Brown. Studies of the metabolism of $\mathrm{I}^{181}$-labeled human transferrin. J. Lab. clin. Med. 1963, 61, 363.

\section{SPECIAL NOTICE TO SUBSCRIBERS}

Post Offices will no longer forward the Journal when you move.

Please notify The Journal of Clinical Investigation, Business Office, 10 Stoughton Street, Boston, Mass. 02118, at once when you have a change of address, and do not omit the Zip Code number. 